\title{
Creating cell engineering fascia on the basis of various types of biocompatible materials and autologous cells for the surgical treatment of genital prolapse
}

\begin{abstract}
Keywords: surgical treatment of pelvic prolapse, cell engineering construction, mesh implant, dermal fibroblasts, biocompatible matrix, pelvic prolapsed
\end{abstract}

\section{Introduction}

Genital prolapse is one of the most frequently occurring problems of modern medicine. Rather often this disease is manifested in reproductive period and binding progressive character. According to World statistic, the frequency of genital prolapse ranges from 2-3\% in developed countries to $85 \%$ in Asian countries. ${ }^{1,2}$ It is considered, that the prevalence rate of genital prolapse will rise in a ten-year projection. So, in the USA about 20,000 women have surgical manipulations on this problem every year.

According to the literature (Krasnopolsky, Adomyan, Kulakov), visceroptosis and genital evisceration occur at $15-30 \%$ of women, and women after 50 the frequency of prolapse is increased to $40 \% .^{2-7}$ Visceroptosis and genital evisceration is often followed by functional changes in the local organs, which makes this problem more relevant (significant), ${ }^{3-8}$ So, $70.1 \%$ of patients with genital prolapse have incontinence of urine, defecatory disorder $36.5 \%$, dyspareunia $-53.3 \%,{ }^{10}$ The main treatment is surgery. All methods of surgical correction can be divided into 3 groups: 1 -(redressement) reconstruction with self-tissue; 2 -using biological or synthetic materials; 3 - vagine obliteration, ${ }^{9,11}$ Self-tissue perineoplasty come amid high frequency of backset (from 30\%). ${ }^{12,13}$ Many authors explain this with the loss of strength of connective tissue and muscular carcass. Such surgical operations can recover it only by $50 \% .^{14,15}$ That is why the surgery is spreading now.

Using mesh prosthesis in perineoplasty is less frequency of backset (5-40\%). In comparison with other methods. But these methods have their own sequelae (mesh associated). The main of it are: anabrosis (erosion) of mesh protesis, infection complications, mesh-associated retraction, dyspareunia, chronical (chronic) pelvic pain. ${ }^{22}$ Thereby, it is necessary to improve implant materials by making new cell engineering constructions renewal of Fascial defects of pelvic floor. ${ }^{16-18}$

\section{Case report}

\section{Materials and methods}

the matrices used polypropylene mesh (of non-absorbable fibers made from isotactic crystalline stereoisomer of polypropylene), composite mesh (consisting of Polyglactin and polypropylene fibers), mesh of vicryl and biological implant (containing porcine dermal collagen).

\author{
Volume 4 Issue 4 - 2018 \\ Sulina YY,' Lyundup AV,' Ishchenko AI,' \\ Alexandrov LS,' Sinyakin IS, ${ }^{2}$ Barinova AR' \\ 'IM Sechenov First Moscow State Medical University, Russia \\ ${ }^{2}$ Medical University of Vienna,Austria
}

\begin{abstract}
Correspondence: Sulina Yana Yurévna, Obstetrics and Gynecology Department One medical faculty, I.M. Sechenov First Moscow State Medical University, Moscow, Russia, Email ya.suli.na@gmail.com
\end{abstract}

Received: August II, 2018 | Published: August 31,2018

As a cellular material: dermal fibroblasts isolated from a piece of skin epidermis of laboratory rat Wister, $5 \times 5 \mathrm{~mm}$ in size. The dermal fibroblasts of the laboratory rat of the third passage were applied to the mesh samples. From each grid under sterile conditions was cut fragment of a square form of $10 \times 10 \mathrm{~mm}$. For each snippet of the displayed grid was added $250 \mu 1$ of cell suspenzii (400 thousand cells). Incubated at $37^{\circ} \mathrm{C}$ in a moist environment containing $5 \% \mathrm{CO}_{2}$ for 60 minutes. Then, in each hole was added $2 \mathrm{ml}$ of culture medium, continuing incubation in the same conditions. On the 14th day there was a closure of mesh cells, the formation of a monolayer of dermal fibroblasts (Figure 1).

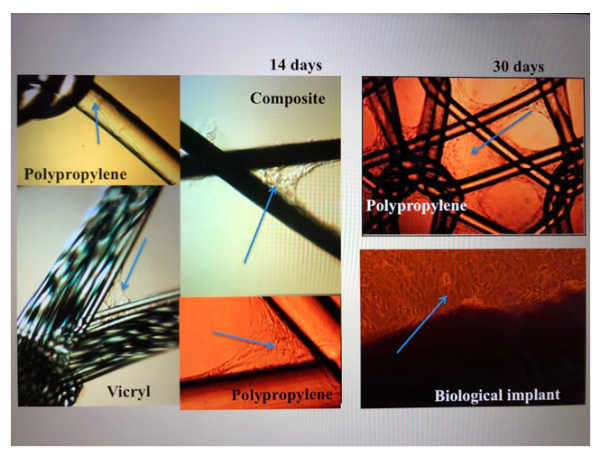

Figure I Meshes with skin fibroblasts. The arrows point to the colony cells. Light microscopy, increase $\times 100$, phase contrast.

The samples were stained with acridine orange and etidium bromide. The dye stock solution was prepared as follows: $1.5 \mathrm{mg}$ of acridine orange and $5.0 \mathrm{mg}$ of ethidium bromide were dissolved in 0.1 $\mathrm{ml}$ of $95 \%$ ethanol, then $5 \mathrm{ml}$ of distilled water was added. The dye working solution was prepared from the stock solution by dissolving in 100x PBS volume. For staining, pre-washed from the medium for cultivation, the samples were poured with a working solution of dyes 
for 5 minutes. As a result, acridine orange staining occurs living cells, and etidium bromide - dead cells.

\section{Microscopy}

The fluorescence localization of the samples was recorded using a laser scanning confocal microscope LSM-710 (Carl Zeiss Microscopy, Jena, Germany). Stained samples from in vitro cultivation cups were transferred to sterile Petri dishes with a thin glass bottom $0.16 \mathrm{~mm}$ thick in PBS solution. To obtain images, we used the EC Plan-Neofluar 10x/0.3/M27lens. Excitation of the fluorescence of acridine orange was performed with the laser wavelength of $488 \mathrm{~nm}$, the fluorescence recorded in the range of 495 to $545 \mathrm{~nm}$. The excitation of the fluorescent ethidium bromide was produced by a laser with a wavelength of $561 \mathrm{~nm}$, fluorescence was recorded in the range of $580 \div 690 \mathrm{~nm}$. 3D images were obtained by reconstructing Z-stacks obtained by scanning in the mode of $1024 \times 1024$ pixels $(850 \times 850 \mu \mathrm{m})$, with a confocal aperture of $34 \mu \mathrm{m}$ in diameter, scanning speed of $0.64 \mu \mathrm{s} /$ pixel. As a result, we obtained an overlay of fluorescent images of the localization of acridine orange (green), etydium bromide (red) and the image obtained in the mode of transmitted light (in 3D-reconstruction mode of transmitted light is not included in the overall overlay).

\section{Confocal microscopy}

Confirmation of initial antifouling surfaces filaments dermal fibroblasts with further filling meshes cells was performed using confocal microscopy. Start of closed cells cells began 10-14 days after cell seeding on the keeper. Closing of the majority of the cells of the multilayer cellular structure was observed for 30 days (Figure 2) and the closure of all cells was observed at 45 days of cultivation (Figure $3)$.

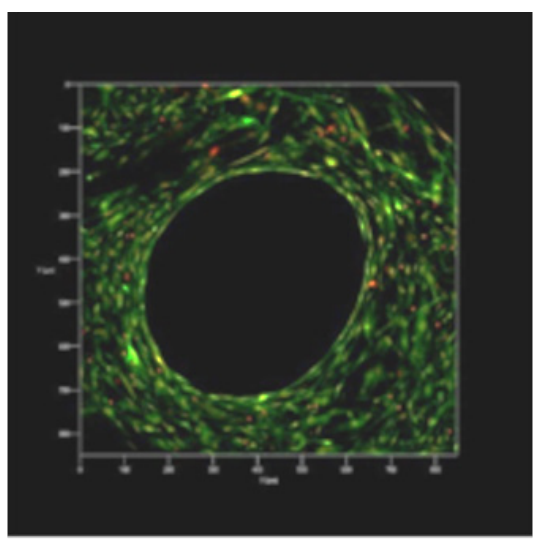

Figure 2 Polypropylene mesh. Confocal laser microscopy: the remaining uncovered grid cell with live dermal fibroblasts located in several layers, 30 days of cultivation. Coloration: acridine orange (green color) living cells, and ethidium bromide (red color) - dead cells. Increase $x 40$.

\section{Graft transplantation}

Implantation surgery of cell-engineering construction received by adhesion autologous dermal fibroblasts (during 2 weeks) on polypropylene, composite, vicryl mesh and biological implant were provided to a group, consisted by (of) 12 lab animals in the subaponeurotic space of the interlaced area, under the fascia of the trapezius muscle (Figure 4)Two cell-engineering structures on each side were placed in the resulting "pockets" for $1.0-1.5 \mathrm{~cm}$, retreating from the spine to the area of the vanes of laboratory animals. With general anesthesia (Zoletil 100) strictly on abdominal midline $2 \mathrm{~cm}$ lower xiphisternum longitudinally skin was split and subcutaneous fat (length $3-4 \mathrm{~cm}$ ).

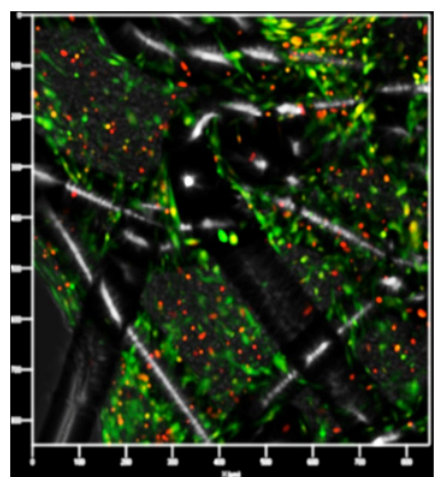

(A)

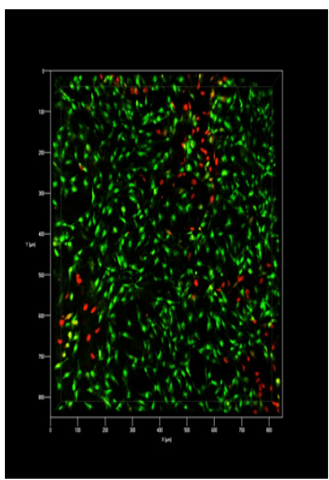

(B)
Figure 3 A - Polypropylene mesh. B - Biological implant. Confocal laser microscopy: the remaining uncovered grid cell with live dermal fibroblasts located in several layers, 30 days of cultivation. Coloration: acridine orange (green color) living cells, and ethidium bromide (red color) - dead cells. Increase $\times 60$.

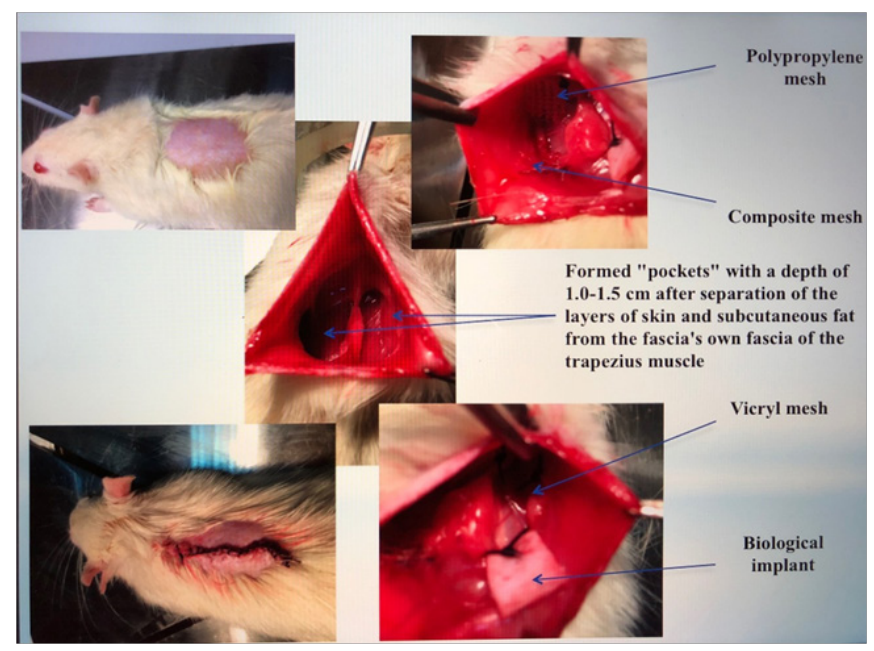

Figure 4 Implantation surgery of cell-engineering construction received by adhesion autologous dermal fibroblasts (during 2 weeks) on polypropylene, composite, vicryl mesh and biological implant.

\section{Results}

On day 3, adherence of dermal fibroblasts to filaments of reticular implants (predominantly at the corners) was observed, and after 14 days - the growth of colonies (some of the cells were closed by cells). At 30 days, the viability of cells on cell-engineering structures was assessed. With the help of confocal microscopy, it was possible to compare the thickness of the layer of the formed tissue: the best effect was possessed by a biological implant (a continuous layer of tissue was formed), followed by a biodegradable reticular scaffold of vicryl, and a longer period for the formation of a connective tissue layer had a biodegradable polypropylene fiber mesh.

An evaluation of the tissue response to tissue engineering construction was made at the time of sampling for histological 
examination $(7,14,21$ days after implantation) on different types of biodegradable, biodegradable and composite matrix coated with dermal fibroblasts.

The tissue engineering construction based on polypropylene material demonstrated the best perception of the tissue of the recipient: the least expressed cellular reaction, sufficient plethora of capillaries, less pronounced edema of surrounding tissues.

The tissue engineering construction based on the vikril surgical mesh on the 21 st day after implantation showed complete fusion with the adjacent tissues, and fibrous tissue formed around the filaments of the mesh, forming a single dense structure.

The tissue engineering construction on the basis of the composite mesh to the final control point of the study formed a pseudocapsule around the implant material, represented by a young connective tissue made of collagen fibers and a fibroblast-collagen carcass around the mesh.

The tissue reaction to the implantation of a tissue engineering construction based on a biological implant from porcine collagen was represented by neovascularization of the implant, and the activity of the inflammatory reaction corresponded to the normal course of the wound process.

Immunohistochemical study was conducted to assess the degree of proliferation (protein Ki-67), apoptosis (Caspase-3, Caspase-9), anti-apoptosis (Bcl-2), angiogenesis (CD 31, Col3A1). As a result of implantation of the fabric engineering design on the basis of the polypropylene mesh, it was noted: a decrease in the apoptotic effect at a rather high level of the antiapoptotic effect, a decrease in the degree of proliferation, an increase in the level of angiogenesis. Covering resorption meshes with autologous dermal fibroblasts leads to a decrease in programmed cell death and an increase in the density of the vasculature, which explains the reduced risk of rejection of the tissue engineering construct by the rat organism. As a result of implantation of the tissue engineering construction on the basis of the composite mesh, it was noted: moderately expressed levels of antiapoptotic, apoptotic effects, medium degree of proliferation, marked decrease in the degree of angiogenesis.

As a result of implantation of a tissue engineering construction based on a biological implant, there were observed: mild proliferative activity of cells and activation of proapoptotic Caspasa-3-dependent processes leading to apoptotic death of fibroblasts.

\section{Discussion}

In the study, autologous dermal fibroblasts were sown on polypropylene, vicryl, composite meshes and biological implants without any auxiliary materials such as collagen, laminin, fibronectin, etc. All seeded dermal fibroblasts formed a complete monolayer of living cells on the surfaces of mesh threads. Our results show that dermal fibroblasts can be a potential source of cells for tissue-oriented fascial equivalents for the reconstruction of the pelvic floor.

\section{Conclusion}

Conventional implants from inert materials can eliminate only the physical and mechanical deficiencies of damaged tissues. The goal of tissue engineering is the restoration of biological (metabolic) functions, that is, the regeneration of tissue, rather than simply replacing it with synthetic material. ${ }^{19,20}$ The development of cellular technologies and the involvement of new methods of molecular biology opens the way for the restoration of significant defects in tissues and organs using in vitro artificial tissues. Cellular material can be represented by cells of the regenerated tissue or stem cells, ${ }^{21,22}$ Stem cells are undifferentiated cells that can divide, self-renew and differentiate into one or more types of specialized cells. In gynecology, cellular material obtained by directional differentiation of bone marrow stem cells, umbilical cord blood or adipose tissue is used. ${ }^{18}$ Our work is of a pilot nature.

The preliminary data obtained make it possible to draw the following conclusions:

a. It is possible to create a fabric engineering design based on the coating of a polypropylene, vicryl, composite and biological implant with a dermal fibroblast culture;

b. It is necessary to continue this study to obtain statistically reliable results on the biocompatibility of these structures.

\section{Acknowledgements}

There has been no singnificant financial support for this work that could have influenced its outcome. We confirm that the manuscript has been read and approved by all named authors and that there are no other persons who satisfied the criteria for authorship but are not listed. We further confirm that the order of authors listed in the manuscript has been approved by both of us. We confirm that we have given due consideration to the protection of intellectual property associated with this work and that there are no impediments to publication.

\section{Conflicts of interest}

The author declares there are no conflicts of interests.

\section{References}

1. Mawajdeh SM, Al-Qutob RJ, Farag AM, et al. Prevalence and risk factors of genital prolapse A multicenter study. Saudi Med J. 2003;24(2):161-165.

2. Adamyan LV, Blinov MA, Sasha BE. Modern concepts of surgical descent and prolapse of female genital mutilation/Mater Intern Congress: Endoscopy in the diagnosis, treatment and monitoring of women's diseases. 2000. p. 622-635.

3. Buyanova SN, Smolnova TY, Ioseliani MN. The pathogenesis of descent and prolapse of internal genital organs. Vestn Ros Associ Akush hin. 2002;(1):77-79.

4. Ishchenko AI, Shulutko AN, Alexandrov LS. Simultantnye and combined surgery in gynecology. A Practical Guide: Moscow M. 2007;1-12.

5. Kulakov VI, Adamyan LV, Mynbayev OA. Surgical treatment of descent and prolapse of the uterus and vagina. Oper Gene Heer Energy M Medicine. 2000;741-760.

6. Samuelsson EC, Tibblin G, Svärdsudd KF, et al. Signs of genital prolapsed in a Swedish population of woman 20 to 59 years of age and possible related factors. Amer J Obstet Gynaec. 1999;180(2):299-305.

7. Popov AA. Surgical treatment of complicated and uncomplicated forms of genital prolapsed. Mater Ros II Forum "Mother and Child" M. 2000. 271 p.

8. Manukhin IB, Dayanov FV, Kolesov AA. Some of the results of operations in endoskopichesih genital prolapsed. Endoscopy hin M.2000;508-509.

9. Bachaev VV, Gunter VE, Dambaev GZ. Medical Materials and 
Implants with Shape Memory. Implants with Shape Memory in Gynecology.Tomsk: Publishing house of the MIC; 2010. 220 p.

10. Elmer C, Blomgren B, Falconer C, et al. Histological inflammatory response to transvaginal polypropylene mesh for pelvic reconstructive surgery. J Urol. 2009;181(3):1189-1195.

11. Aboushwareb T, Wezel F, Southgate J, et al. Is tissue engineering and biomaterials the future for lower urinary tract dysfunction (LUTD)/ pelvic organ prolapse (POP)? Neurourol Urodyn. 2011;30(5):775-782.

12. Jurgens WJ, Oedayrajsingh Varma MJ, Helder MN, et al. Effect of tissue harvesting site on yield of stem cells derived from adipose tissue: implications for cell-based therapies. Cell Tissue Res. 2008;332(3):415426.

13. Man Jung Hung, Mei Chin Wen, Ying Ting Huang, et al. Fascia tissue engineering with human adiposederived stem cells in a murine model: Implications for pelvic floor reconstruction. J Formos Med Assoc. . 2014;113(10):704-715.

14. Butteri L, E Bichon, L Hench. Introduction to tissue engineering Biomaterials, artificial organs and tissue engineering Technosphere.2007;214-222.

15. Paltsev MA, Akchurin RS, Alexandrov MA. Stem cell biology and cellular technologies. 2009;1:89-106.
16. Li H, Fu X. Mechanisms of action of mesenchymal stem cells in cutaneous wound repair and regeneration. Cell Tissue Res. 2012;348371.

17. Shi LB, Cai HX, Chen LK, et al. Tissue engineered bulking agent with adipose-derived stem cells and silk fibroin microspheres for the treatment of intrinsic urethral sphincter deficiency. Biomaterials. 2014;35(5):1519-1530

18. Kleinert S, Horton R. Retraction-Autologousmyoblasts and fibroblasts versus collagen [corrected] for treatment of stress urinary incontinence in women: A [corrected] randomised controlled trial. Lancet. 2008;372(9641):789-790

19. Mathias T, Souzan S, Rita Gobet. Adipose-Derived Stem Cells (ASCs) for Tissue Engineering. 2011:1-9.

20. Altman GH, Diaz F, Jakuba C. Biomaterials. 2003;24:401-416.

21. Wiesmann HP, Meyer U. Biomaterials. In: Meyer U, Meyer T, Handschel J, editors. Fundamentals of tissue engineering and regenerative medicine. Berlin Heidelberg: Springer-Verlag: 2009. p. $457-468$.

22. Dwyer PL. Evolution of biological and synthetic grafts in reconstructive pelvic surgery. Int Urogynecol J Pelvic Floor Dysfunct. 2006;17(Suppl 1):5-10. 